\title{
A Study of ISA Engagement at an Autonomous Management Education and Research Institute, Madhya Pradesh
}

\author{
Divya Sharma*
}

\begin{abstract}
Employee engagement has remained a major concept in HRD studies, whether it is related to OCBs, task performance, or climate. Different measures have been developed to estimate employee engagement level. One of the recent scales developed is the ISA engagement scale by Soane, et.al.(2012), and it has three facets of employee engagement i.e. intellectual engagement, social engagement and affective engagement. This model was built on the theory of employee engagement by Kahn (1990). The ISA engagement scale has been used in the present research to study the degree of employee engagement at various levels in an autonomous management education institute. Various levels were studied on the basis of job category, age and experience using simple statistical calculation. Among all the three facets of ISA engagement scale, social engagement was found to be low among less experienced and lower age groups in this institute. A slight difference was observed in the average degree of employee engagement on the basis of job tenure. This study contributes to further research done on the third facet i.e. social engagement.
\end{abstract}

Keywords: Employee engagement, ISA engagement scale.

*Academic Associate, IIM Indore; divyas@iimidr.ac.in 


\section{Introduction}

Higher education institutions play a significant role in contribution to the growth of every nation. No organization or institute can stand up without its building block i.e. Human Resources. It is therefore needed to take a count of the human resources working in these institutes. However, a very good cultural environment has been observed in major education institutes of India, and employees working there are supposed to be highly engaged. This research contributes to this line to study the engagement level of one among the top ranked management education institutes of India.

Kahn (1990) portrayed engagement as unique and significant motivational thought: the harnessing of an employee's full self in terms of physical, cognitive, and emotional energies to work role performances (Rich, Lepine \& Craford, 2010). However, it does not explain that individuals can choose to invest their affective, cognitive, and physical energies all together into role performances (Kahn,1990, 1992). Engaged individuals are described as being psychologically present, fully there, attentive, feeling, connected, integrated, and focused in their role performances (Rich, Lepin \& Craford, 2010).

Definitions of employee engagement stated by various authors:

Kahn(1990) coined the term and defined it as "The harnessing of organization members' selves to their work roles; in engagement, people employ and express themselves physically, cognitively, and emotionally during role performance".

Maslach et. al. (2001) declared that "Engagement is characterized by energy, involvement, and efficacy".

Schaufeli et. al. (2002) described it as "A positive, fulfilling, workrelated state of mind that is characterized by vigor, dedication, and absorption".

Harter et. al. (2002) stated it as "The individuals' involvement and satisfaction with as well as enthusiasm for work". 
Shuck and Wollard (2010) defined it as "An individual employee's cognitive, emotional, and behavioral state directed toward desired organizational outcomes".

Fully engaged employees are more productive (Saks, 2006). Engaged employees contribute significantly to gaining and sustaining competitive advantage (Macey \& Schneider, 2008). Engagement serves to fulfill the human spirit at work, and disengagement is viewed as the decoupling of the self from the work role and involves people withdrawing and defending themselves during role performances (May, Gilson \& Harter, 2004). Employee engagement needs further development if it is to make a strong contribution to HRD field (Soane, et.al., 2012). Building on the basic concepts of Kahn's theory of employee engagement and other distinctively significant theories related to motivation, need, working environment, social organizational context, activation, affect, valence, goal attainment, and cognition, the ISA engagement scale has been developed to fill the gap of integrated social engagement aspect in the previous scales.

The ISA engagement scale was proposed on the basis of three prime requirements of engagement. First is the personal need for meaningfulness of work, second is activeness, and third is affect. To date, there has been little discussion about the theoretical foundations for the multi-dimensional nature of engagement (Soane, et.al., 2012).

Soane, et.al. (2012) projected three facets of ISA engagement scale:

- Intellectual engagement: This facet was proposed on the basis that engagement is not only to fulfill duties. It also signifies that there should be cognition. If the employee is intellectually active, it will consequently result into work performance. In brief, intellectual engagement is defined as "the extent to which one is intellectually absorbed in work".

- Affective engagement: This term has been proposed to clear the association in terms of affect. It has been defined as "the extent to which one experiences a state of positive affect relating to one's work role". 
- Social engagement: This is the third facet in which it has been assumed that there is a requirement for workers to work collectively, but until late it was not included in the facets of employee engagement. This is defined as "the extent to which one is socially connected with the working environment and shares common values with colleagues".

Kahn (1990) speculated that individuals differ in the degree to which they plunge themselves in their roles. Different measures have been developed to measure employee engagement level. The ISA engagement scale has been used in the present research to study the degree of employee engagement at various levels in an autonomous management education institute. This study contributes to further research of the third facet i.e. social engagement.

\section{Objectives}

1. To study the degree of employee engagement at various levels in an autonomous management education institute.

2. To study the impact of employment status, age and experience on ISA engagement.

\section{Method}

\section{Sample and procedure}

The sample of the present study comprised of 63 administrative staff ofan autonomous management education and research institute. Questionnaires were distributed and collected during working hours. Due to confidentiality some of the respondents did not mention their names. However, a confidentiality maintaining statement was already mentioned in the survey questionnaire. The information was collected in December 2014. All of the responses were collected personally in hardcopy. The average experience of the sample was found to be 6.43 years. The sample consisted of 36 males and 27 females aged between 23 years to 59 years (average age $=30.12$ ). The education qualifications of sample ranged from graduate to masters. Characteristics of participants are provided in Table1. 
Table 1

\begin{tabular}{|l|l|c|c|}
\hline \multicolumn{4}{|c|}{ Characteristics of Participants } \\
\hline Item & \multicolumn{1}{|c|}{ Category } & Frequency & Percentage \\
\hline Employment status & Permanent & 23 & 25.92 \\
\hline & Contractual & 40 & 74.07 \\
\hline Gender & Male & 36 & 55.55 \\
\hline & Female & 27 & 44.44 \\
\hline Years of experience & $0-5$ & 38 & 66.66 \\
\hline & $5.1-10$ & 15 & 12.96 \\
\hline & $10+$ & 10 & 9.25 \\
\hline Age distribution & $21-30$ & 47 & 81.48 \\
\hline & $31-40$ & 12 & 12.96 \\
\hline & $41+$ & 4 & 1.85 \\
\hline
\end{tabular}

\section{Measures}

Employee engagement (EE) was measured using the Intellectual, Social, Affective engagement scale (ISA Engagement scale) developed by Soane, et.al. (2012). The scale includes three facets: Intellectual engagement(three items, e.g., "I focus on my work", "I concentrate on my work", I pay a lot of attention to my work"); Social engagement (three items, e.g., "I share the same work values as my colleagues", "I share the same work goals as my colleagues", "I share the same work attitudes as my colleagues"); Affective engagement (three items, e.g., "I feel positive about my work", "I feel energetic in my work", I am enthusiastic in my work"). All nine items are rated on a seven-point Likert scale ranging from 1 ("Strongly Disagree") to 7 ("strongly Agree").For the present study, Cronbach alpha value for the scale was found to be .79, which is above the acceptable level of .70 .

The ISA Engagement scale incorporated all the three requirements of Kahn's theory i.e. Work-role Focus, Activation and Positive Affect. It also includes the social facet of engagement. Soane, et.al., (2012) demonstrated the internal reliability was confirmed and construct validity. 


\section{Results}

The average score of employee engagement was found to be 5.18 (see table2), which is above the average level of engagement for the employees in the institute under study. It could be higher if the social engagement facet had a good score. If the social aspect would improve, then the overall engagement level will increase by a substantial degree. However, this score is also beneficial for the institute. Out of the three items, affective engagement scored the highest. Intellectual engagement scored lower with a minute difference. Yet, there is negligible difference in both these facets. The social facet scored lower as compared to the other two. If we go for an item-wise analysis of means, "I concentrate on my work" has the highest score; however, all the six items of intellectual and affective engagement are having negligible difference, "I share the same work attitude" scored the lowest. This signifies that individuals are engaged in concentrating in their work, but have different work attitude at workplace in the present institute. That different employees have different work values is resulted here.

Table 2: Employee engagement

\begin{tabular}{|l|c|}
\hline \multicolumn{1}{|c|}{ Dimension } & Mean \\
\hline Employee engagement & 5.18 \\
Intellectual engagement & 5.72 \\
Social engagement & 4.06 \\
Affective engagement & 5.78 \\
\hline
\end{tabular}

It has been observed that social engagement has the highest difference between both types of employees. However, affective engagement has scored the lowest difference. This signifies that contractual employees have a lower level of engagement in comparison to permanent employees. Social engagement here shows greater deviations. 
Table 3: ISA engagement score based on job tenure

\begin{tabular}{|l|c|c|c|c|}
\hline \multicolumn{4}{|c|}{ Differences in ISA engagement levels based on employment status } \\
\hline Dimension & \multicolumn{2}{c|}{ Permanent } & \multicolumn{2}{c|}{ Contractual } \\
\hline & Mean & SD & Mean & SD \\
\hline Intellectual engagement & 6.18 & 0.91 & 5.48 & 1.28 \\
Social engagement & 4.88 & 1.38 & 3.6 & 1.75 \\
Affective engagement & 6.14 & 0.97 & 5.6 & 1.2 \\
\hline
\end{tabular}

Based on total experience, employees having experience of $10+$ years scored the highest and employees having experience of 0-5 years scored the lowest, however, it was observed that there was no significant difference in score of intellectual and affective engagement in $0-5$ and 5-10 years. Social engagement scored the lowest in 0-5 years and highest in $10+$ years.

Table 4: ISA engagement levels based on total experience

\begin{tabular}{|l|c|c|c|}
\hline \multicolumn{4}{|c|}{ Difference in ISA engagement levels based on total experience } \\
\hline Dimension & $0-5$ years & $5-10$ years & $10+$ years \\
\hline & Mean & Mean & Mean \\
\hline Intellectual engagement & 5.62 & 5.64 & 6.22 \\
\hline Social engagement & 3.84 & 4.15 & 4.7 \\
\hline Affective engagement & 5.69 & 5.71 & 6.26 \\
\hline
\end{tabular}

Due to sample size constraints it was not possible to differentiate the degree of engagement on the basis of age. However, social engagement noticed to have some significant level of variations to an increasing degree. Further research can be done on this facet on the basis of age group for improved results.

Table 5: ISA engagement levels based on age

\begin{tabular}{|l|c|c|c|c|c|c|}
\hline \multicolumn{7}{|c|}{ Difference in ISA engagement levels based on age } \\
\hline Dimension & $20-30$ years & $31-40$ years & \multicolumn{2}{|c|}{$40+$ years } \\
\hline & Mean & SD & Mean & SD & Mean & SD \\
\hline Intellectual engagement & 5.64 & 1.22 & 5.78 & 1.14 & 6.5 & 0.79 \\
\hline Social engagement & 3.78 & 1.75 & 4.75 & 1.55 & 5.25 & 0.75 \\
\hline Affective engagement & 5.65 & 1.17 & 6.08 & 0.99 & 6.5 & 0.79 \\
\hline
\end{tabular}




\section{Discussion}

The reliability of engagement measure was moderate for overall items (alpha=0.79). It has been observed that social engagement scored the lowest on each basis. The ISA engagement scale encompasses three items in social engagement facet. Work value, work attitude and work goals. The present study shows a lower score in these items in comparison to other two facets. It proposes that further studies should be done to determine the extent to which this social aspect affects the level of employee engagement. However, the present study shows a significant level of overall engagement.Yet, employees in the present institute, having different perception of work attitude, work values and work goals, incorporate a good score of engagement. More research is needed to examine the social aspect included in ISA engagement scale.

\section{Managerial Implications}

This analysis was conducted to study the degree of employee engagement with the help of ISA engagement scale. The engagement level was found to be significantly above than average. However the social aspect unexpectedly scored the lowest among all facets. Sharing of goals increase effectiveness, enable greater collaboration, communication, and a greater degree of unity (Davis, 2013).There is a need to improve this in the present institute.

\section{Limitations and scope for future research}

Participants' views could have some degree of bias, as they are dependent on their perception. Time and sample size was the second major constraint. If the sample size could have been large it could lead to a better result. Present study lacks in examining the reasons behind the low score of social aspect of employee engagement. This study further suggests the use of other statistical methods to determine more accurate and correlated results. It can also be proposed to research further about social engagement, in that how much it affects the engagement level of employees. 


\section{Conclusion}

This study was conducted to observe the degree of employee engagement at various levels in an autonomous management education institute. It shows that ISA engagement level is significantly above the average score. Among three facets of ISA engagement scale, affective engagement scored the highest. However, no significant difference was observed between intellectual and affective engagement.

Need for further research has been observed to study the impact of tenure, age and experience on employee engagement.

\section{References}

Davis A. (2013). Retrieved January 17, 2013 from http://adriandavis.com/.

Harter, J.K., Schmidt, F.L. \& Hayes, T.L. (2002). Business-unit-level relationships between employee satisfaction, employee engagement, and business outcomes: A meta analysis. Journal of Applied Psychology, 87, 268-279

Kahn, W.A. (1990). Psychological conditions of personal engagement and disengagement at work. Academy of Management Journal, 33(4), 692-724.

Kahn, W.A. (1992). To be fully there: Psychological presence at work. Human Relations, 45, 321-349.

Macey, W., \& Schneider, B. (2008). The meaning of employee engagement. Industrial and Organizational Psychology, 1, 3-30.

Maslach, C., Schaufeli, W.B., \& Leiter, M.P. (2001). Job burnout. Annual Review of Psychology, 52, 397-422.

May, D.R., Gilson, R.L., \& Harter, L.M. (2004). The psychological conditions of meaningfulness, safety and availability and the engagement of the human spirit at work. Journal of Occupational and Organizational Psychology, 77, 11-37.

Rich, B.L., Lepine, J.A., \& Crawford, E.R. (2010). Job engagement: Antecedents and effects on job performance. Academy of management journal, 53(3), 617-635.

Saks, A.M. (2006). Antecedents and consequences of employee engagement. Journal of Managerial Psychology, 21, 600-619. 
Schaufeli, W., \& Salanova, M. (2007). Work engagement: An emerging psychological concept and its implications for organizations. In S. W. Gilliland, D. D. Steiner, \& D. P.

Schaufeli, W.B., Bakker, A.B., \& Salanova, M. (2006). The measurement of work engagement with a short questionnaire: A cross-national study. Educational and Psychological Measurement, 66, 701-716.

Schaufeli, W.B., Salanova, M., Gonzalez-Roma, V., \& Bakker, A.B. (2002). The measurement of engagement and burnout: A two sample confirmatory factor analytic approach. Journal of Happiness Studies, 3, 71-92.

Shuck, B., \& K. Wollard. 2010. Employee engagement and HRD: A seminal review of the foundations. Human Resource Development Review, 9(1), 89-110.

Soane, E., Truss, C., Alfes, K., Shantz, A., Rees C., \& Gatenby, M. 2012. Development and application of a new measure of employee engagement: the ISA Engagement Scale. Human Resource Development International, 15(5), 529-547. 